\title{
Experimental Study on Physical Similar Model of Fault Activation Law Based on Distributed Optical Fiber Monitoring
}

\author{
Dingding Zhang $\mathbb{D},{ }^{1,2}$ Yanyan Duan, ${ }^{1,3}$ Wengang Du, ${ }^{1}$ and Jing Chai ${ }^{1,2}$ \\ ${ }^{1}$ School of Energy Engineering, Xi'an University of Science and Technology, Xi'an 710054, China \\ ${ }^{2}$ Key Laboratory of Western Mine Exploitation and Hazard Prevention, Xi'an 710054, China \\ ${ }^{3}$ China United Northwest Institute for Engineering Design and Research Co., Ltd., Xi'an 710077, China \\ Correspondence should be addressed to Dingding Zhang; zhangdd@xust.edu.cn
}

Received 5 September 2021; Accepted 18 September 2021; Published 26 September 2021

Academic Editor: Gan Feng

Copyright (c) 2021 Dingding Zhang et al. This is an open access article distributed under the Creative Commons Attribution License, which permits unrestricted use, distribution, and reproduction in any medium, provided the original work is properly cited.

\begin{abstract}
The impact ground pressure in coal mining is closely related to the fault structure, and the fault activation pattern is different when the working face advances along the upper and lower plates of the fault, respectively. In this paper, the F16 positive fault in the southern part of Yima coalfield is used as a prototype to carry out the physical similar model test simulating the process of the working face advancing from the upper and lower plates of the fault, and PPP-BOTDA optical fiber sensing technique is used to study the overburden deformation law and fault activation law when the working face is located in the upper and lower plates of the fault, respectively. The study shows that the key stratum breakage is closely related to the fault movement, and the shear stress concentration range occurs within the key stratum. The additional shear stress concentration at the fault surface caused by the working face advancing in the lower plate is much larger than that at the upper plate, which is the reason for the serious fault destabilization phenomenon at the lower plate. The upper rock layer on the fault face is affected by the mining action of the working face before the lower one, and the working face is affected by the fault in a larger range when advances in the lower plate than that in the upper plate, and the risk of fault activation instability occurs earlier when the working face advances in the lower plate than that in the upper plate. The distributed optical fiber sensing technology is used to verify the basic conclusions that the impact of the working face advancing from the lower plate is much greater than that from the upper plate, which is more likely to cause fault activation. The preferential placement of the working face in the upper plate in the fault area will be beneficial to mine pressure control. The results of the study provide an experimental basis for the application of distributed optical fiber sensing technology to the study of fault activation law.
\end{abstract}

\section{Introduction}

Impact ground pressure caused by coal and rock mass faults is a phenomenon of the violent release of energy due to sudden relative misalignment of the upper and lower plates of fault caused by coal mining activities, which is characterized by high release energy and high seismic level and has become one of the major geological hazards of mining in the world, affecting the safe and efficient mining of underground mineral resources $[1,2]$. Fault activation is an important cause of impact ground pressure induced by structural instability of coal rock in the fault area and associated disasters such as mine water breakout, roof accident, and coal and gas protrusion $[3,4]$. Therefore, it is of great theoretical significance to study the mechanism of fault misalignment-type impact ground pressure occurrence and fault activation characteristics.

Many scholars have conducted a lot of research on the mechanism of mining-induced fault activation instability [5, 6]. Ji et al. [7] studied the variation characteristics of stress near the fault by numerical simulation for the working face under the fault parallel and perpendicular to the fault. Zhang et al. [8] conducted the experiment of thrust fault slipping under unloading. The differential stress variation was studied and the evolution of displacement and strain field along the fault. Jiang et al. [9] constructed the Coulomb 
shear model and analyzed the degree of fault activation hazard under the conditions of different coal mining methods. Wang et al. [10] analyzed the stress environment in the tectonic zone from the perspective of tectonic formation mechanism and concluded that the superposition of fault tectonic stress and mining stress that would induce impact ground pressure disaster; Alber et al. [11] analyzed the relationship between excavation location and fault tangential displacement increment by using two-dimensional finite element means. Wang et al. [12] studied the evolution of the contact stress state of the two disks of the fault under different advancement methods by numerical simulation. $\mathrm{Li}$ et al. [13] studied the influence of slip instability on impact ground pressure at the fault surface by using similar simulation tests and numerical simulation. The current research on the fault stress-strain distribution law is based on numerical simulation, and the selection of boundary conditions and intrinsic model affects the accuracy of numerical simulation.

Physical model experiments can visually reflect the interaction process between the surrounding rock and the engineering body, and distributed fiber optic sensing technology can respond to the changes of external strain, stress, and other parameters in a timely manner. The fiber itself has the advantages of good durability, high sensitivity, and internal stress-strain measurement, which is widely used in various fields. Chai et al. [14, 15] applied BOTDA distributed fiber optic sensing technology to three-dimensional model test monitoring, proposed the concept of distributed fiber optic frequency shift average change degree, and concluded that the fiber optic frequency shift average change degree can reflect the overlying rock layer deformation, incoming pressure, and its changes. Piao et al. used Brillouin optical time-domain analysis (BOTDA) optical fiber distributed sensing technology. This paper studied the strain distribution rule and movement characteristics of strata under reamer-pillar mining [16]. Moffat et al. [17] used a distributed fiber optic sensing monitoring system based on BOTDR to displacement monitoring of the top of the tunnel and the two gangs to achieve rock deformation assessment during mining activities. Buchoud et al. [18] carried out DOFSbased surface settlement displacement monitoring using artificial collapse pits to simulate surface collapse pits and achieved submillimeter level surface vertical displacement measurements. The application of distributed fiber optic sensing technology enables real-time, wide-area, fully distributed monitoring.

In this paper, the coevolutionary characteristics of the overlying rock movement and fault movement in the quarry under different advancement methods under positive fault conditions and the interaction mechanism between the two are studied through similar material modeling experiments with fiber optic sensing monitoring technology as the main monitoring means to analyze the fault activation characteristics caused by different advancement methods and explore the feasibility of fiber optic sensing technology in similar simulation tests of fault activation.

\section{Fault Activation Test Principle}

2.1. Principle of PPP-BOTDA. The propagation of light in an optical fiber produces three scattering signals: Rayleigh scattering, Raman scattering, and Brillouin scattering. Brillouin scattered light is caused by nonlinear interactions between incident light and phonons that are thermally excited within the light propagation medium. This scattered light shifts in frequency by a Brillouin shift and propagates in the opposite direction relative to the incident light [19-21]. Figure 1 shows the monitoring principle of BOTDA.

Compared to BOTDA, PPP-BOTDA (i.e., Pulse-Prepump-Brillouin Optical Time Domain Analyzer) [22], higher spatial resolution can be obtained. This is done by loading an appropriate pulse-prepumped light to preexcite phonons before introducing the pulsed light (pumped light.) The PPP-BOTDA has a smaller half-value full width and higher frequency resolution of the Brillouin gain spectrum, achieving a spatial resolution of $10 \mathrm{~mm}$ and $0.0025 \%$ strain test accuracy.

It has been found that there is a relationship between Brillouin frequency shift (BFS) $v_{B}$ and temperature $T$ or strain $\varepsilon$; the relationship can be expressed as follows [23]:

$$
V_{B 2}=V_{B 1}+C_{T}\left(T-T_{0}\right)+C_{\varepsilon} \Delta \varepsilon,
$$

where $v_{B 2}$ is Brillouin scattered frequency shift with strain at a certain temperature $T, v_{B 1}$ is Brillouin scattered frequency shift without strain at temperature $T_{0}, C_{T}$ is the sensitivity coefficient of the fiber to temperature, $C_{\varepsilon}$ is the sensitivity coefficient of the fiber to strain, and $T_{0}$ is the initial temperature. It is worth noting that the temperature-induced Brillouin frequency shift is much smaller than that caused by strain $\left(0.002 \% /{ }^{\circ} \mathrm{C}\right)$. Therefore, when measuring the Brillouin frequency shift caused by strain, if the temperature changes within $5^{\circ} \mathrm{C}$, the temperature can be ignored.

2.2. Fault Destabilization Mechanism under the Influence of Mining. Before the coal seam is mined, the rock bodies above and below the fault are in equilibrium; after mining, the additional shear stress is generated at the fault face under the superposition of ground stress and mining disturbance stress [24]. When the working face is far away from the fault, the fault is weakly affected by the mining and the additional shear stress is small. At this time, the stress values of the rock bodies above and below the fault are within the peak strength and in a stable state. As the working face gradually approaches the fault, the overlying rock fracture development leads to the reduction of bearing capacity. The load is transferred to the surrounding rock, and the additional shear stress of the rock near the fault surface increases. When the working face is mined to a certain position, the total stress is greater than the peak strength, the fault becomes unstable, and the fault will be destabilized and activated.

Taking the positive fault as the object of study, the working face is located in the upper plate advancing toward the fault, and the equilibrium structural mechanical model of the top plate in the fault-affected area is shown in Figure 2(a). When the working face advances toward the 

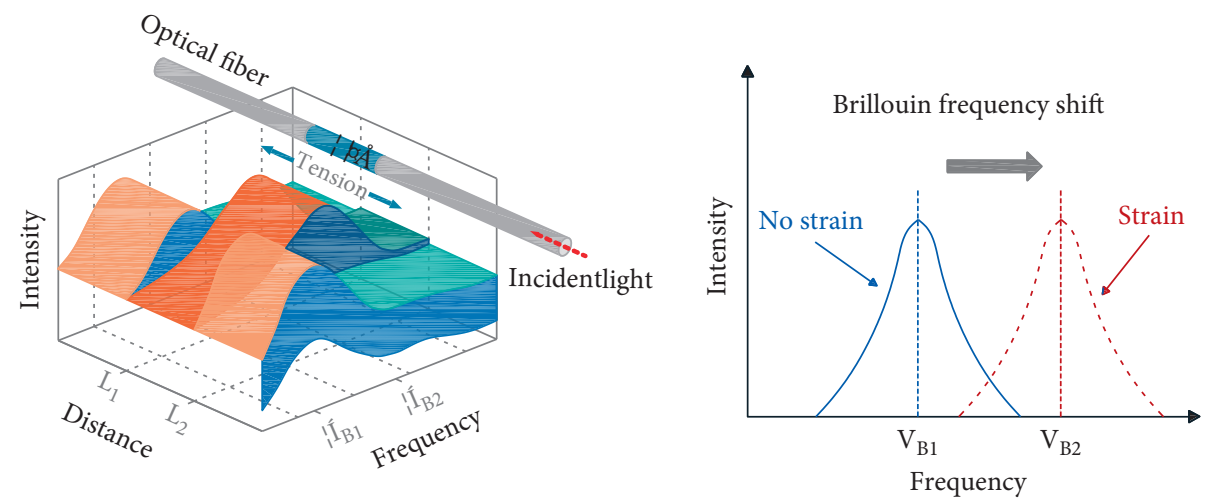

Figure 1: Monitoring principle of BOTDA.

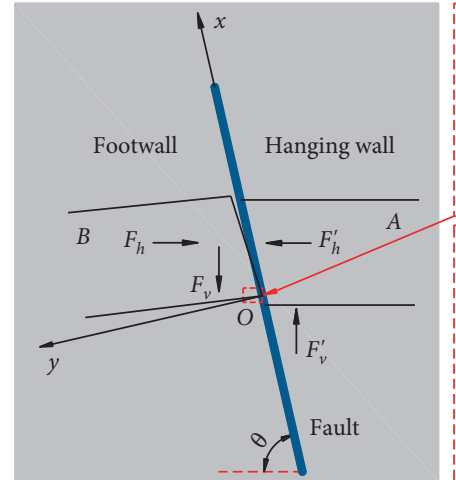

(a)

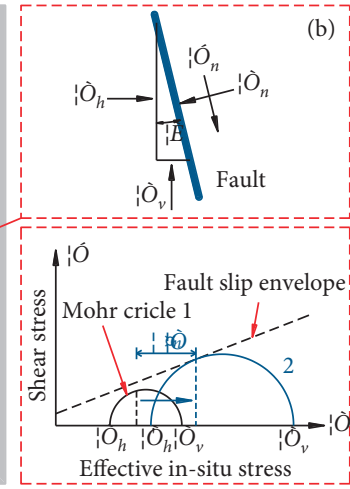

(c)
Figure 2: Schematic diagram of the forces and fault stresses in the rock mass adjacent to a staggered positive fault.

fault, the overlying rock layer collapses toward the mining area. The uncollapsed part of the hard rock layer forms the masonry beam structure, and the mutually cemented rock blocks in the masonry beam structure can not only transfer the vertical force, thus playing a supporting role for the overlying rock layer, but also can transfer the horizontal force, which has an impact on the fault [25]. Under the influence of mining overburden load, the lower rock "block B" is subjected to the combined horizontal force $F_{h}$ and vertical force $F_{v}$. A tiny unit at the fault face is taken to establish a fault plane mechanical model, as shown in Figure 2(b). The fault activation is determined by the relationship between the positive and shear stresses at the fault face, and the positive stress $\tau_{n}$ and shear stress $\sigma_{n}$ are functions of the maximum principal stress, the minimum principal stress, and the fault dip angle, which can be expressed as follows:

$$
\begin{aligned}
\tau_{n} & =\frac{1}{2}\left(\sigma_{v}-\sigma_{h}\right) \sin (2 \theta), \\
\sigma_{n} & =\frac{1}{2}\left(\sigma_{v}+\sigma_{h}\right)+\frac{1}{2}\left(\sigma_{v}-\sigma_{h}\right) \cos (2 \theta),
\end{aligned}
$$

where $\theta$ is the fault dip angle, $\sigma_{v}$ is the maximum principal stress of the fault, and $\sigma_{h}$ is the minimum principal stress of the fault.
According to the Moore Coulomb yield criterion, the Mohr circle 1 is far from the fault sliding envelope when it implies that no-fault sliding will occur [26], as shown in Figure 2(c). As the coal seam is mined, the overburden load above the mining area is transferred to the fault, which makes the fault positive stress increment $\left|\Delta \sigma_{\mathrm{n}}\right|$ continuously larger [27], prompting the Mohr circle to move, and the fault reaches the limit equilibrium state when Mohr circle 2 is tangent to the fault sliding envelope. Activation and sliding of the fault occur when the fault shear and positive stresses satisfy the following conditions:

$$
\Delta \tau_{r}=\left|\tau_{r}-\tau\right| \leq\left|\Delta \sigma_{n}\right| \tan \varphi_{f}
$$

where $\Delta \tau_{r}$ is the fault shear stress increment, $\tau_{r}$ is the shear stress corresponding to the increase in positive fault stress by $\Delta \sigma_{n}$, and $\varphi_{f}$ is the internal friction angle of the rock mass.

From the above analysis, fault activation is the shear deformation of a fault under shear stress. The fault surface shear can be obtained indirectly by measuring the maximum principal stress, minimum principal stress, or positive stress at fault, or by directly measuring the shear to assess the activation state of the fault. Due to the complexity of the fault configuration, all the above parameters are difficult to test. Therefore, the direct measurement of fault face shear strain using a distributed fiber optic sensing method offers the possibility to study the activation pattern of faults.

\section{Similar Material Model Experiments}

3.1. Similar Material Model Construction. The experimental prototype was selected to simulate the 21221 header workings of the 2\# coal seam of the Qianqiu coal mine in Yima, Henan Province, and the F16 positive fault located in the southern part of the Yima coalfield, which has an extended length of $24 \mathrm{~km}$, an east-west orientation, a tendency of $160 \sim 170^{\circ}$, an inclination of $15 \sim 35^{\circ}$, a drop of $50 \sim 450 \mathrm{~m}$, and a horizontal misalignment of $120 \sim 1080 \mathrm{~m}$. The break and drop tend to increase gradually from east to west. The break and drop have a gradually increasing trend from east to west. In this paper, two two-dimensional plane stress models with the same lithological parameters and fault structure are built for comparison experiments, and the model dimensions are $150 \times 70 \times 20 \mathrm{~cm}$ 
TABle 1: Similar model lithology parameters.

\begin{tabular}{lcccccc}
\hline Lithology & $\begin{array}{c}\text { Density } \\
\left(\mathrm{kg} / \mathrm{m}^{3}\right)\end{array}$ & $\begin{array}{c}\text { Compressive strength } \\
(\mathrm{MPa})\end{array}$ & $\begin{array}{c}\text { Elastic } \\
\text { modulus (GPa) }\end{array}$ & $\begin{array}{c}\text { Poisson's ratio } \\
\text { Angle of internal } \\
\text { friction }\left(^{\circ}\right)\end{array}$ & $\begin{array}{c}\text { Matching number (quartz } \\
\text { sand:gypsum:lime) }\end{array}$ \\
\hline $\begin{array}{l}\text { Medium } \\
\text { sandstone }\end{array}$ & 2440 & 53.21 & 30.02 & 0.40 & 35.0 & $8: 4: 6$ \\
Mudstone & 2461 & 25.56 & 8.85 & 0.26 & 30.0 & $9: 4: 6$ \\
$\begin{array}{l}\text { 2\# coal } \\
\text { Siltstone }\end{array}$ & 1440 & 22.45 & 3.42 & 0.16 & 26.9 & $9: 2: 8$ \\
Fine & 2707 & 35.19 & 23.85 & 0.19 & 29.5 & $8: 2: 8$ \\
sandstone & 2873 & 45.03 & 17.66 & 0.14 & 29.2 & $8: 3: 7$ \\
\hline
\end{tabular}

(length $\times$ height $\times$ width). Model I simulates the working face advancing from the lower plate of the fault to the fault; model II simulates the working face advancing from the upper plate of the fault to the fault. The model geometric similarity constant is 200 , the capacity similarity constant is 1.67 , and the stress similarity constant is 334 . The experiment simulates the overlying rock thickness of $137 \mathrm{~m}$, the coal seam thickness of $10 \mathrm{~m}$, the fault dip angle of $60^{\circ}$, and the height drop of $8 \mathrm{~m}$ between the upper and lower plates.

Similar material model experiments for the selection of model similarity ratios are often determined by the study object, the purpose of the experiment, and the size of the experimental bench [28]. According to the above principles, the geometric similarity constant $C_{l}$ for this experimental model was first determined to be 200. According to the similarity criterion, the displacement similarity constant $C_{s}$ is 200 .

The time similarity constant $C_{t}$ is as follows:

$$
C_{t}=\frac{t_{p}}{t_{m}}=\sqrt{C_{l}}=14.14
$$

The unit weight similarity condition $C_{P}$ is as follows:

$$
C_{p}=\frac{\gamma_{p}}{\gamma_{m}}=1.67
$$

where $\gamma_{P}$ is the $2 \#$ average unit weight of overlying strata of the coal seam, taken as $2.5 \mathrm{~g} / \mathrm{cm}^{3}$, and $\gamma_{M}$ is the average bulk density of similar material model, taking $1.5 \mathrm{~g} / \mathrm{cm}^{3}$.

Stress similarity constant $C_{\sigma}$ is as follows:

$$
C_{\sigma}=C_{l} C_{p}=167 \text {. }
$$

According to the actual rock strength parameters shown in Table 1, river sand is selected as the aggregate, and the large white powder $\left(\mathrm{CaCO}_{3}\right)$ as well as gypsum $\left(\mathrm{CaSO}_{4}\right)$ as the cementing material, and the dosage ratio of the above three is reconciled based on the similarity criterion to simulate different rock layers. Based on the cross-sectional area of the model frame and the thickness of the rock (coal) seam in the model, the volume of each similar material required can be calculated, and then the weight of each rock (coal) seam similar material can be calculated based on the capacity and proportion of similar materials.

\subsection{Experimental Test System and Experimental Procedure}

3.2.1. Optical Fiber Test System. Two distributed fiber optic sensors perpendicular to the rock layer and one inclined distributed fiber optic sensor along the fault surface were buried in models I and II to test the overburdened vertical strain and fault tangential strain. The sensing fibers in Model I are numbered V11, V12, and F11, and the sensing fibers in Model II are numbered V21, V22, and F21, where F11 and F21 are arranged along the fault plane, and the distributed sensing fiber system and the specific arrangement are shown in Figure 3. The specific locations of sensing fibers in the fiber test system are shown in Figure 4, and the lengths of the test systems are $18.553 \mathrm{~m}$ and $25.523 \mathrm{~m}$. The spatial location of fiber sensing in the model was determined by the watershed heating method before the experiment.

In order to accurately obtain the deformation information inside the rock formation, the parameters of the NBX-6055 strain analyzer were set as $5 \mathrm{~cm}$ spatial resolution, $2 \times 10^{16}$ averaging times, and $1 \mathrm{~cm}$ sampling interval. $2 \mathrm{~mm}$ diameter single-mode polyurethane tight-sleeve fiber was selected for the experiments, with an elastic modulus of $300 \mathrm{kPa}$, a shear modulus of $3.3 \mathrm{kPa}$, and a density of $25 \mathrm{~g} /$ $\mathrm{cm}^{3}$. The strain calibration coefficient of the fiber is $0.0497 \mathrm{MHz} / \mu \varepsilon$.

3.2.2. Displacement Test. Three sets of percentage meter measurement points $\mathrm{A}, \mathrm{B}$, and $\mathrm{C}$ were arranged at $10.06 \mathrm{~cm}$, $27.32 \mathrm{~cm}$, and $44.64 \mathrm{~cm}$ faults above the lower coal seam, and each set of two percentage meters with a vertical fault surface spacing of $10 \mathrm{~cm}$ was used to test the relative slip of the fault surface, the percentage meters in model I were numbered B-11 16, the percentage meters in model II were numbered B-21 26.

3.2.3. Experimental Process. Both models I and II were excavated after leaving a $10 \mathrm{~cm}$ boundary coal pillar with a mining height of $5 \mathrm{~cm}$. Model I advanced $3 \mathrm{~cm}$ at a time and completed 26 mining cycles for a total advance of $78 \mathrm{~cm}$. Model II completed 30 mining cycles for a total advance of $90 \mathrm{~cm}$.

\section{Distributed Optical Fiber Strain Monitoring Results}

4.1. Fault Surface Strain Monitoring. With the advancement of the working face, the strain changes obtained by the distributed optical fibers laid on the fault face are shown in Figure 5, the lower horizontal coordinate indicates the length along the fault face, and the upper horizontal coordinate indicates the height of the model overburden, the strain values of the monitoring fibers on the fault face at 


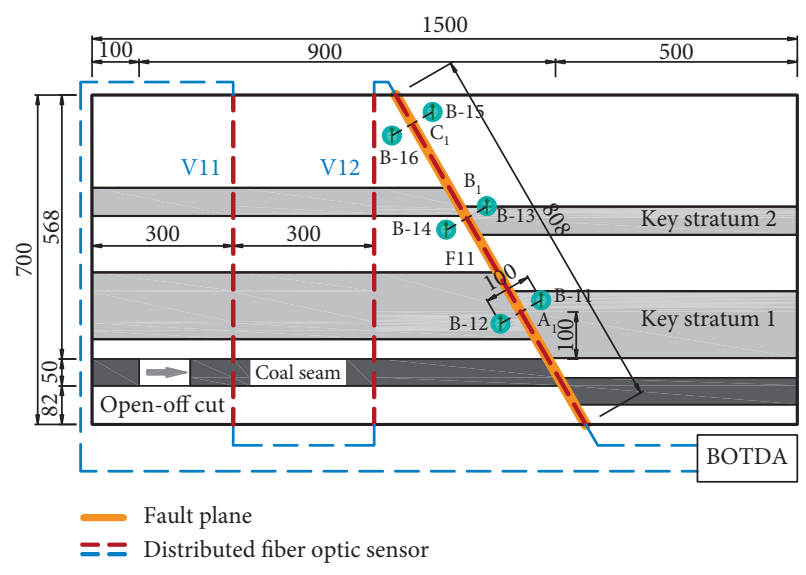

Physical model I

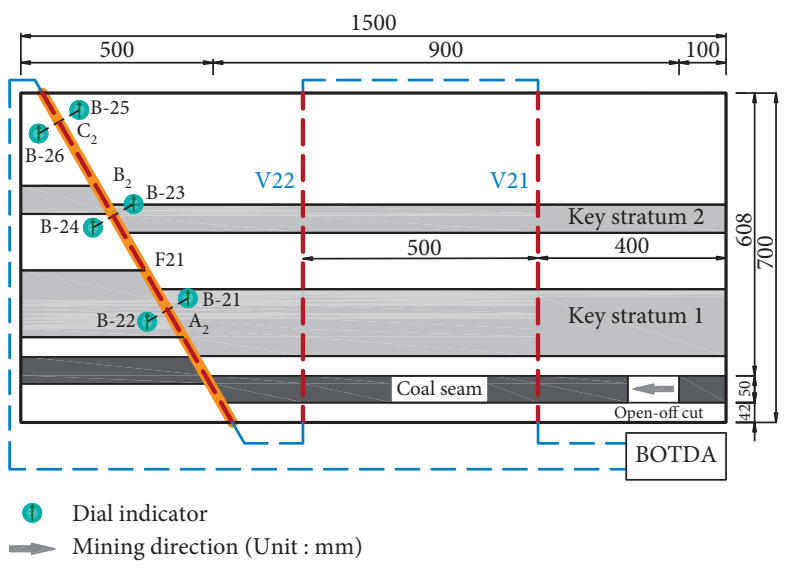

Physical model II

FIgURE 3: Similarity model test system.

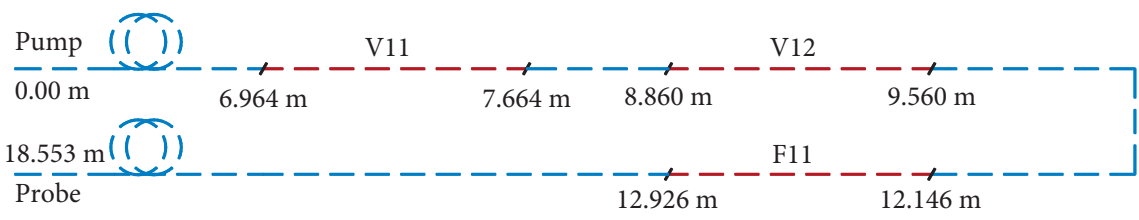

Physical model I

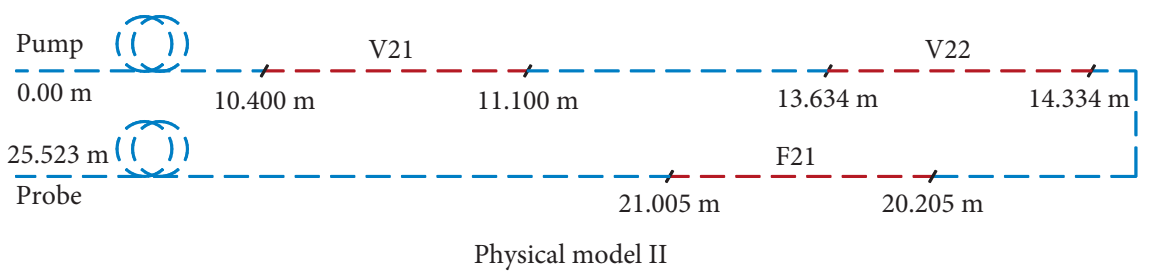

Figure 4: Positioning of sensing optical fiber.

different advancement distances are distributed differently, and the strain tends to increase gradually with the continuous advancement of the working face, indicating that additional shear stress is generated on the fault face under the influence of mining.

4.2. Overburden Deformation Monitoring. The strain variation curves of the overlying rock layer on the working surface derived from the test results of model I fiber V12 and model II fiber V22 are shown in Figure 6, with the vertical coordinates indicating the model height. The fiber is positive for tension and negative for compression. The model temperature change in this experiment is within $5^{\circ} \mathrm{C}$, and the temperature-induced Brillouin frequency shift of the fiber can be neglected, so the strain measured by the fiber optic sensor is the strain generated by the rock mass.

In Figure 6(a), at the stage of $0-51 \mathrm{~cm}$ advance of the working face, the fiber is negative; i.e., the overlying rock is in the state of compressive strain; at the stage of $57 \sim 69 \mathrm{~cm}$ advance, the strain on the V12 monitoring fiber gradually changes from the original compressive strain to the state of tensile strain; at the stage of $69 \sim 72 \mathrm{~cm}$ advance, the tensile strain growth of the V12 monitoring fiber in the range of $31.80 \sim 42.80 \mathrm{~cm}$ above the coal seam decays rapidly. According to a large number of tests, this change in the optical fiber reflects that the overburden rock is in the fallout zone at $14.80 \mathrm{~cm}$ and the upper part is in the mining fracture zone.

In Figure 6(b), the optical fiber is in negative value at the stage of $0 \sim 51 \mathrm{~cm}$ of working face advancement; i.e., the overburden rock is in the state of compressive strain; at the advancement of $57 \sim 69 \mathrm{~cm}$, the V22 monitoring optical fiber still maintains a slow growth of compressive strain; at the advancement of $69 \sim 78 \mathrm{~cm}$, the strain curve of the V22 monitoring optical fiber shows an inverse S-shape; i.e., the rock seam at the lower position is in the state of compressive strain, and the rock seam at the upper position is in the state of tensile strain; at the advancement to $84 \mathrm{~cm}$, the tensile strain of V22 monitoring fiber is greater than $1500 \mu \varepsilon$ in the range of $18.80 \sim 42.80 \mathrm{~cm}$ above the coal seam; the corresponding overburden range is in the bubble fall zone, and the upper part is in the mining fracture zone. Although the curves in Figures 6(a) and 6(b) have differences, their change laws are basically the same, indicating that the overburden rocks of models I and II move with the same law during the mining process. 


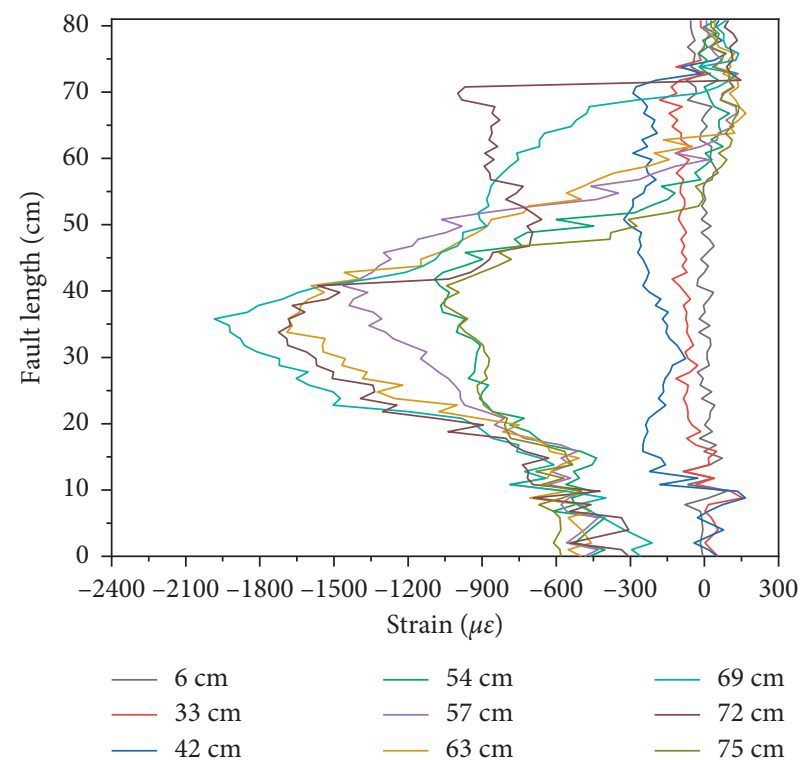

(a)

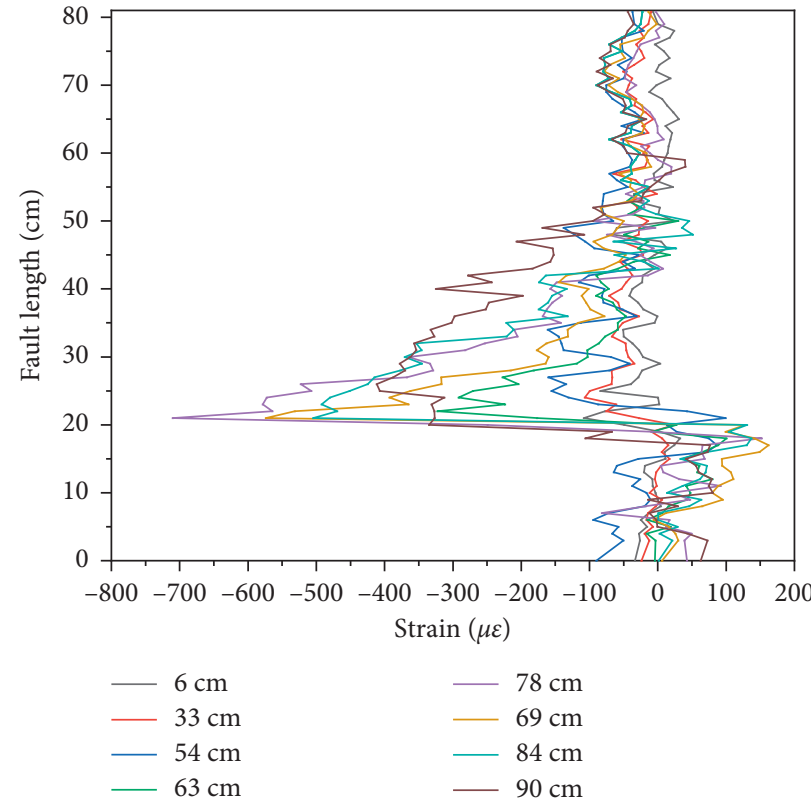

(b)

FIgURE 5: Fault plane strain fiber test results. (a) Fiber F11 of physical model I. (b) Fiber F21 of physical model II.

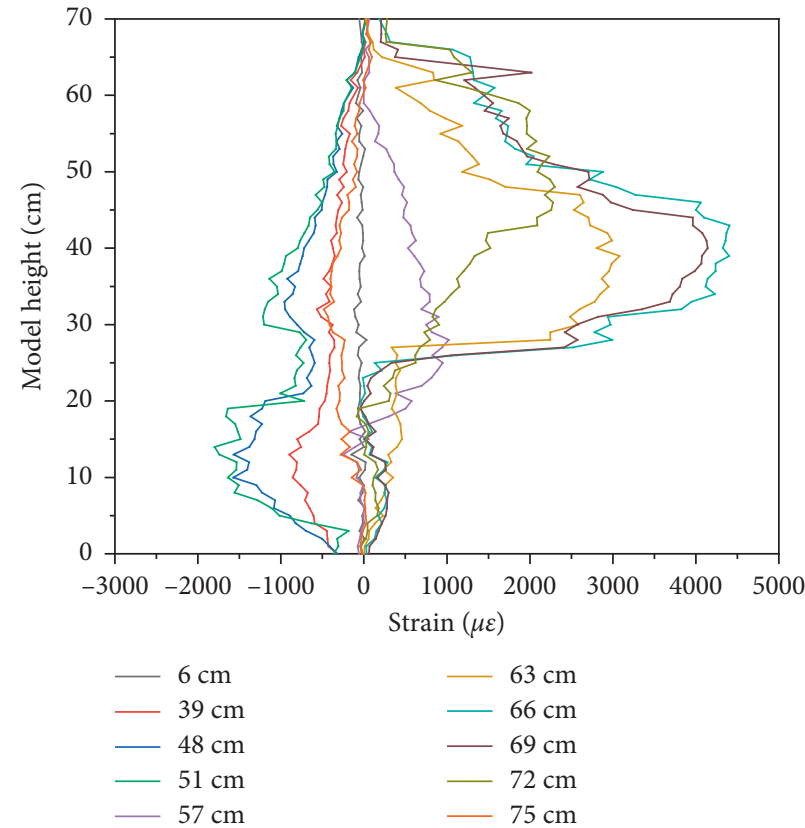

(a)

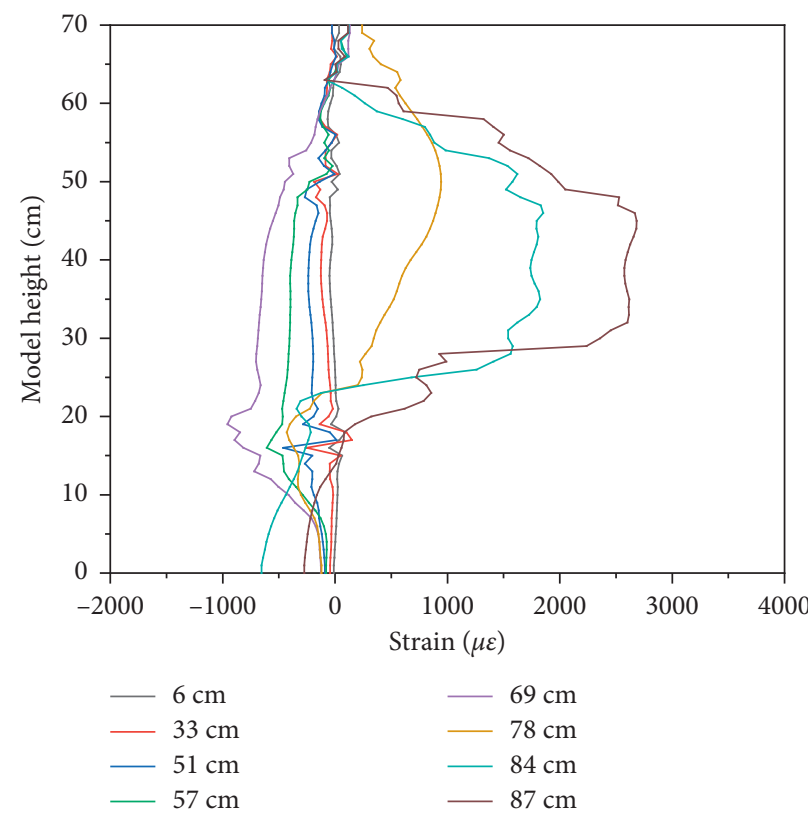

(b)

FIGURE 6: Results of fiber optic testing of overburden deformation at the working face. (a) Fiber V12 of physical model I. (b) Fiber V22 of physical model II.

\section{Analysis on Deformation Law of Overburden}

Figure 7 shows the cloud of strain evolution at the interrupted level during mining at the working face of the lower plate of the similar model I fault, and Figure 8 shows the cloud of strain evolution at the interrupted level during mining at the working face of the upper plate of the similar model II fault. The vertical coordinate indicates the similar model height, and the horizontal coordinate indicates the distance of the working face from the fiber; negative values indicate that the working face has not been pushed through the fiber, and positive values indicate that the working face has been pushed through the fiber. 
(a)

(b) Strain $(\mu \varepsilon)$
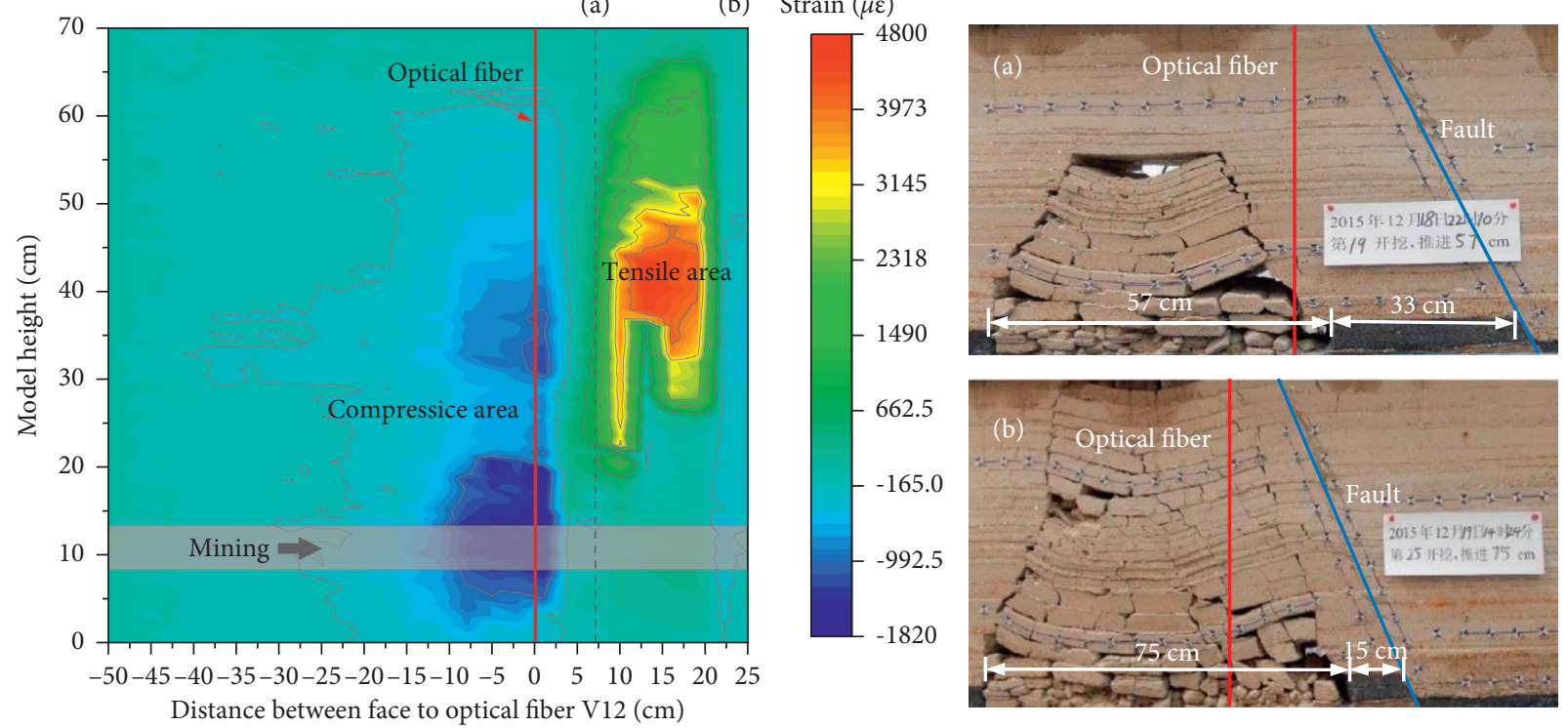

Figure 7: Fault strain evolution in the lower disk of the fault mining.
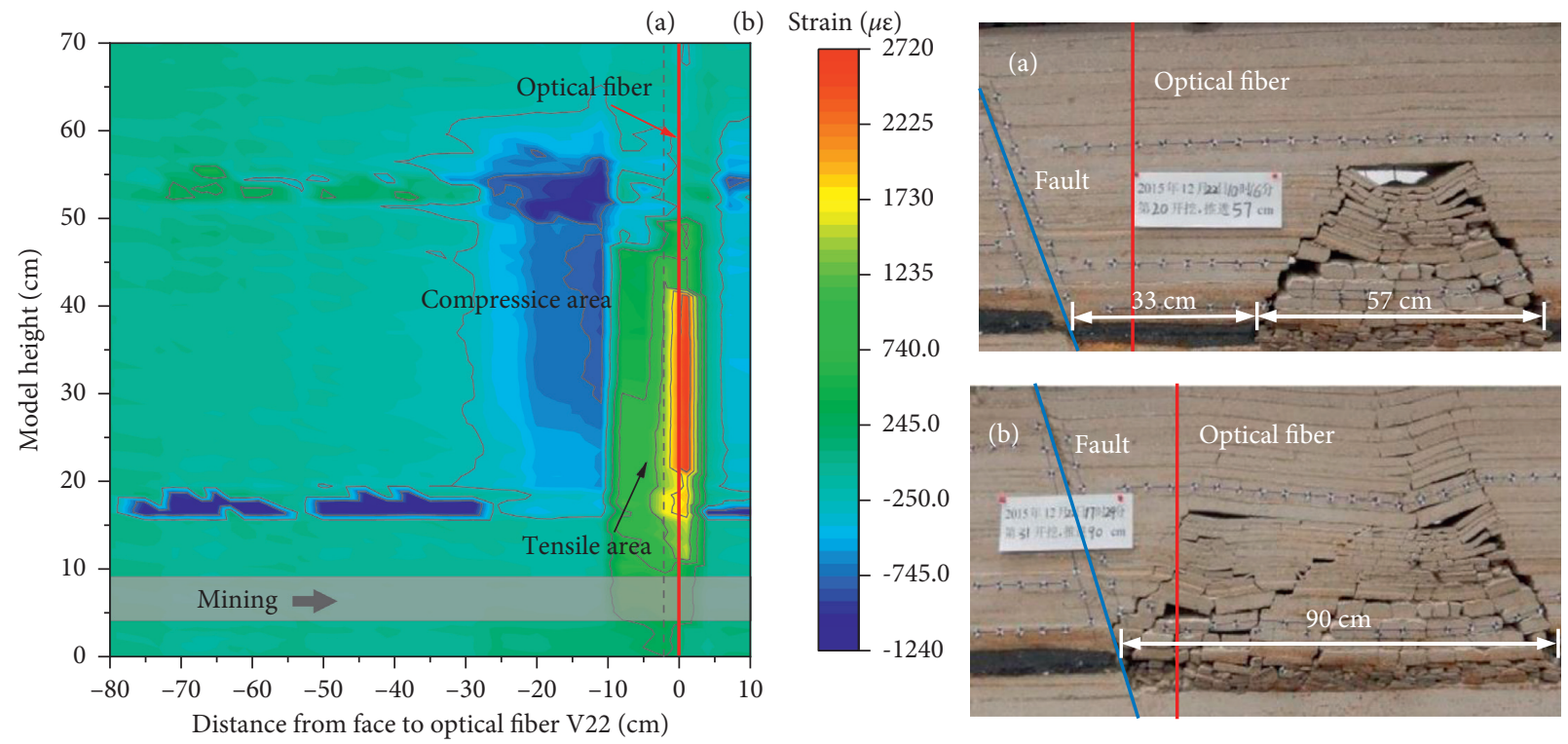

FIGURE 8: Fault strain evolution for mining faults in the upper disk of the fault.

As can be seen from Figure 7, the similar model I working face is $-50 \sim 4 \mathrm{~cm}$ away from the fiber V12, at this time, the working face is pushed $0 \sim 54 \mathrm{~cm}$, the coal wall in front of the working face is affected by the oversupport pressure, the fiber is in negative value that the overlying rock is in the state of compressive strain; when the working face is pushed through the fiber V12 $7 \mathrm{~cm}$, the key stratum 1 breaks, and the overlying rock collapses to the mining area with the key stratum; as shown in Figure 7(a), the fiber changes from compressive strain to tensile strain. As the working face moves away from the fiber, the overlying rock gradually collapses upward, as shown in Figure 7(b), and the tensile strain on fiber V12 gradually increases. When the working face advanced $69 \sim 75 \mathrm{~cm}$, the rock in the mining area where fiber V12 was located was gradually compacted, and the growth of tensile strain in the range of $31.80 \sim 42.80 \mathrm{~cm}$ above the coal seam decayed rapidly and gradually changed to compressive strain. According to a large number of test studies [29], this change in the optical fiber reflects that the corresponding overburden rock $14.80 \mathrm{~cm}$ range is in the bubble fall zone at this time, and the upper part is the mining fracture zone.

From Figure 8, it can be seen that similar model II working face advances from 0 to $51 \mathrm{~cm}$ stage, fiber V22 is negative; i.e., the overburden is in a state of compressive strain. When the working face advances $57 \mathrm{~cm}, 33 \mathrm{~cm}$ away from the fault, the key stratum 1 breaks, as shown in Figure 8(a), and the fiber V22 compressive strain increases 
under the influence of overtopping support pressure. When the working face was advanced $57-69 \mathrm{~cm}$ from the fiber, the V22 monitoring fiber still maintained a slow growth of compressive strain; when the working face was advanced to $78-81 \mathrm{~cm}$, the working face passed the fiber, key stratum 2 broke, and the value of tensile strain in the middle of fiber V22 reached the maximum. When advancing to $84 \mathrm{~cm}$, the tensile strain of V22 monitoring fiber in the range of $18.80 \sim 42.80 \mathrm{~cm}$ above the coal seam was greater than $1500 \mu \varepsilon$; the corresponding overburden range was in the bubble fall zone, and the upper part was the mining fracture zone. At $90 \mathrm{~cm}$, the overburden collapsed to the upper end of the model, and the upper part of the seam structure was relatively intact, forming an obvious articulation structure, and the fault did not show obvious instability, as shown in Figure 8(b).

\section{Analysis of Fault Deformation Evolution Law}

6.1. Analysis of the Strain State of the Fault Face. The strain evolution cloud diagram of the fault surface during the working surface advance is shown in Figure 9. In Figure 9(a), when the working face of model I is $48 \mathrm{~cm}$ away from the fault, the strain of the fiber gradually increases to $-326.57 \mu \varepsilon$, indicating that the additional shear stress at the fault face increases; when it is $33 \mathrm{~cm}$ away from the fault, key stratum 1 breaks, and the strain of the fiber increases to $-1437.89 \mu \varepsilon$ in the range of 9.14 $29.06 \mathrm{~cm}$ above the lower coal seam, this position corresponds to the range of key stratum 1, indicating that key stratum 1 of breaking has an effect on the fault, making the shear stress at the fault face increase. When $21 \mathrm{~cm}$ from the fault, the key stratum 2 breaks, and the strain of the optical fiber in the range of $16.07 \sim 19.53 \mathrm{~cm}$ above the coal seam increases significantly to $-1984.13 \mu \varepsilon$, this position corresponds to the range of key stratum 1, which indicates that the shear stress on the fault surface increases gradually with the mining of the coal seam, and the breakage of key stratum 2 has an impact on the fault. When the working face is $25 \mathrm{~cm}$ from the fault, the overburden collapses to the upper end of the model and the maximum strain in the monitoring fiber decreases to $-1053.42 \mu \varepsilon$. The decrease in strain value at this time is due to the fact that the upper and lower discs of the fault have produced weak cracks and the stress has been released and the stress concentration has been reduced, which makes the strain decrease significantly. However, the overall increase in shear stress at the fault surface is obvious, indicating the possibility of fault slip and the fault entering the "unlocked" instability.

In Figure 9(b), the maximum strain of fiber optic increases to $-161.01 \mu \varepsilon$ when the working face of model II is $36 \mathrm{~cm}$ from the fault; the strain of fiber optic increases to $-574.04 \mu \varepsilon$ at the height of $8.99 \mathrm{~cm}$ above the upper coal seam when the working face is $21 \mathrm{~cm}$ from the fault; the strain of fiber optic reaches the extreme value of $-710.29 \mu \varepsilon$ when the working face is $12 \mathrm{~cm}$ from the fault and the key stratum 2 breaks for the first time, which is located at the height of $7.99 \mathrm{~cm}$ above the coal seam. At the height of $7.99 \mathrm{~cm}$ above, this position corresponds to the range of key stratum 1, indicating that the breakage of key stratum 2 has an effect on the fault. When the working face is $0 \mathrm{~cm}$ from the fault, the fiber strain drops to $-411.691 \mu \varepsilon$, and the location of the shear stress change at the fault face corresponds to the range of the location of key stratum 1 , and the overall trend is gradually increasing, indicating that the fault face is in a certain stress state. It indicates that there is an impact on the fault during the advance of the working face, but it is less affected by mining than in the advance of the lower plate of Model I. This is related to the formation of a stable articulated structure by the breakage of the overburden in Figure 9(b).

As the distance between the working face and the fault decreases, the change curve of the peak strain of the fiber optic at different advancing distances and the overburden height corresponding to the position of the peak strain are shown in Figure 10. As the distance between the working face and the fault decreases, the peak strain of the fiber optic strain of both the lower plate advance and the upper plate advance of the working face shows the law of first increasing and then decreasing. When the distance between the working face and the fault is $48 \mathrm{~cm}$, the peak fiber optic strain increases, indicating that additional shear stress is generated at the fault surface, and the fault is affected by mining to the fault surface $30.1 \mathrm{~cm}$ above the coal seam, so the influence of the fault on the working face is at $48 \mathrm{~cm}$ in front of the fault; the peak fiber optic strain reaches the maximum at $21 \mathrm{~cm}$ from the fault, which is $-1984.13 \mu \varepsilon$. The peak fiber optic strain reaches its maximum at $21 \mathrm{~cm}$ from the fault, which is $-1984.13 \mu \varepsilon$, indicating that the shear stress concentration of the fault reaches the maximum here, and the fault is most likely to be activated, and its location is $15.38 \mathrm{~cm}$ above the coal seam, where the risk of fault activation and destabilization is higher; the overburden height where the maximum fiber optic strain is located gradually decreases as the working face approaches the fault, and the upper part of the fault face is affected by mining before the lower part, which is consistent with the measured results of the fault seismic characteristics during the advance of the working face in the literature [25]. It is consistent with the measured results of the fault seismic characteristics during the advance of the working face. When the working face was advanced, the influence of the fault on the working face was $33 \mathrm{~cm}$ in front of the working face, and the fault was affected by mining at $20.24 \mathrm{~cm}$ above the coal seam; the peak strain reached the maximum at $12 \mathrm{~cm}$ from the fault at the working face, which was $-710.29 \mu \varepsilon$, and the higher risk of fault activation destabilization was located at $8.99 \mathrm{~cm}$ above the coal seam.

From the above analysis, it can be seen that the key stratum breakage is closely related to the fault movement, and the shear stress concentration range occurs within the range of key stratum 1; meanwhile, when the lower plate advances, the additional shear stress generated at the fault surface is about 2.2 times that of the upper plate advance, and the concentration degree is much greater than that of the upper plate advance, which is the reason why the fault destabilization phenomenon of model I is much more serious than that of model II; therefore, the fault is more likely to be activated when the lower plate of the working face 


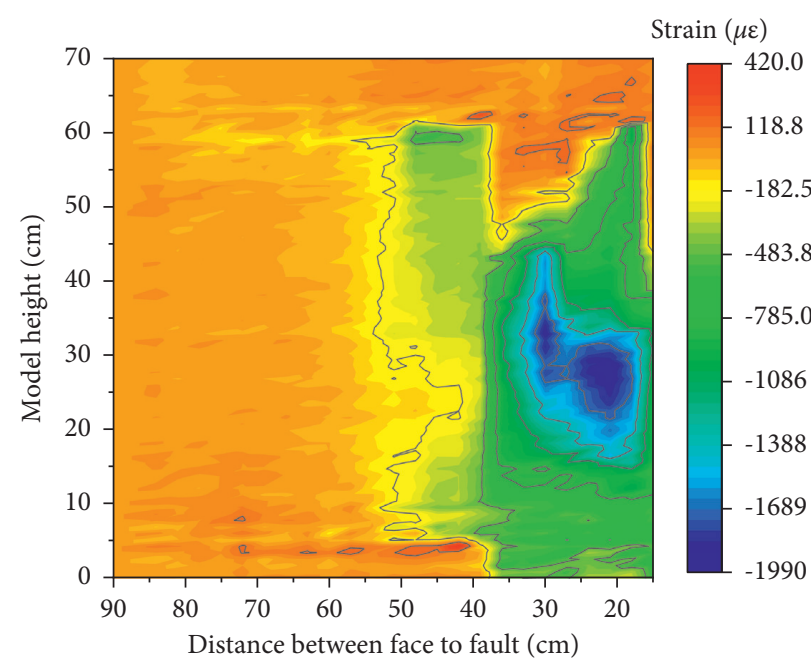

(a)

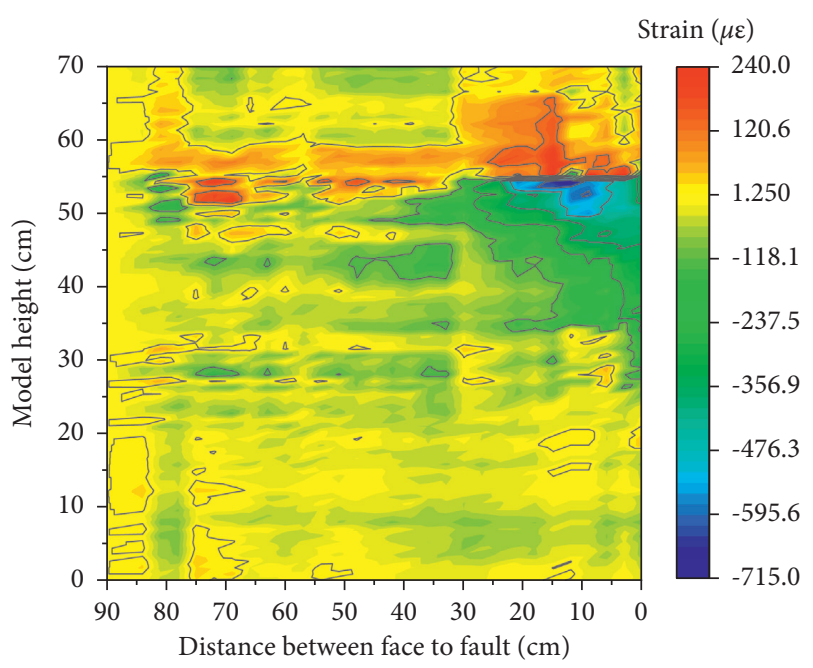

(b)

FIgUre 9: Variation of fault plane strain distribution during coal mining. (a) Physical Model I. (b) Physical model II.

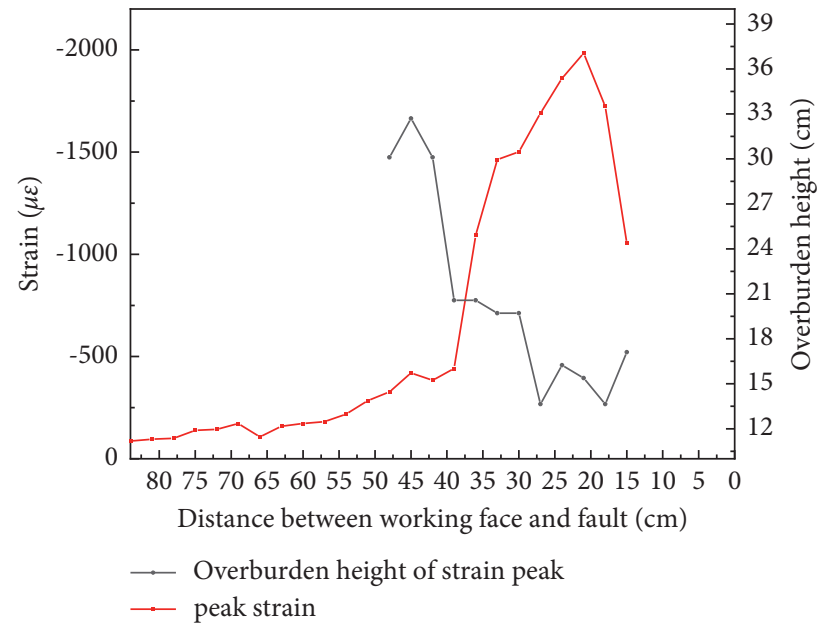

(a)

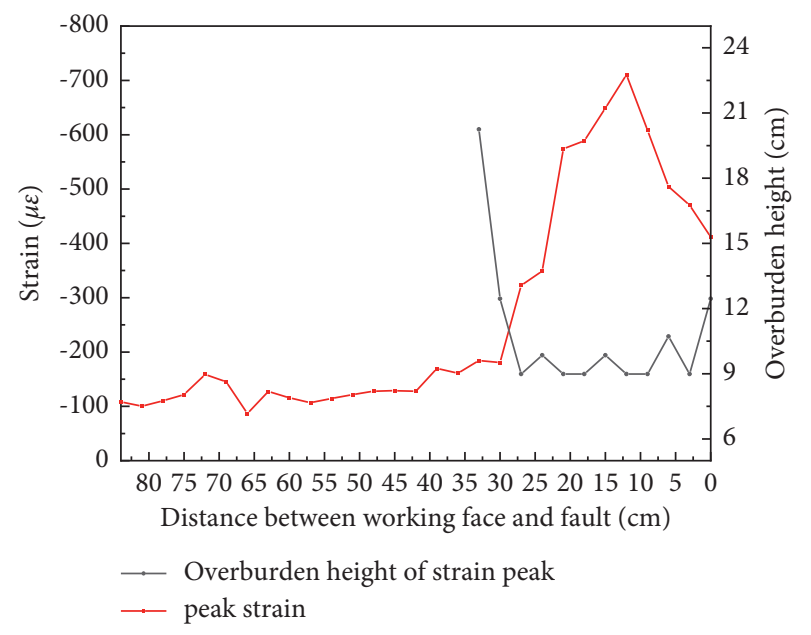

(b)

Figure 10: Variation of peak shear strain at the fault surface at different distances between the working surface and the fault. (a) Physical model I. (b) Physical model II.

advances. The lower plate advancing working face is affected by the fault before the upper plate advances, and its influence range is about 1.5 times of the upper plate advancing. The height of the most easily activated position of the fault face in the lower plate advance is 1.7 times that of the upper plate advance; when the fault has a higher activation destabilization hazard, the distance between the working face and the fault in the lower plate advance is about 1.8 times that of the upper plate advance, indicating that the activation destabilization hazard occurs in the lower plate advance before the upper plate advance.

6.2. Analysis of the Relative Slip of Fault Surfaces. Figure 11 shows the variation curves of the relative displacement of the fault at the three percentage meter measurement points $\mathrm{A}, \mathrm{B}$, and $\mathrm{C}$ during the advance of the working face from the upper and lower plates to the fault, respectively. The relative slip of the fault appeared when the working face of the similar model I and similar model II was $51 \mathrm{~cm}$ and $36 \mathrm{~cm}$ from the fault, respectively; as the working face advanced, the slip of the fault increased gradually in both models, and the slip rate and amount of the fault increased significantly when the working face advanced to $12-33 \mathrm{~cm}$ and $0-18 \mathrm{~cm}$ from the fault, respectively, which was basically consistent with the results of fiber optic strain monitoring on the fault surface. The maximum relative displacements of the three measurement points $\mathrm{A}, \mathrm{B}$, and $\mathrm{C}$ of the similar model I are $0.29,4.33$, and $5.20 \mathrm{~mm}$ respectively, while the three measurement points of similar model II are 0.24, 0.97, and $0.62 \mathrm{~mm}$ respectively, and the difference between the corresponding point displacements is $1.2-8.4$ times. 


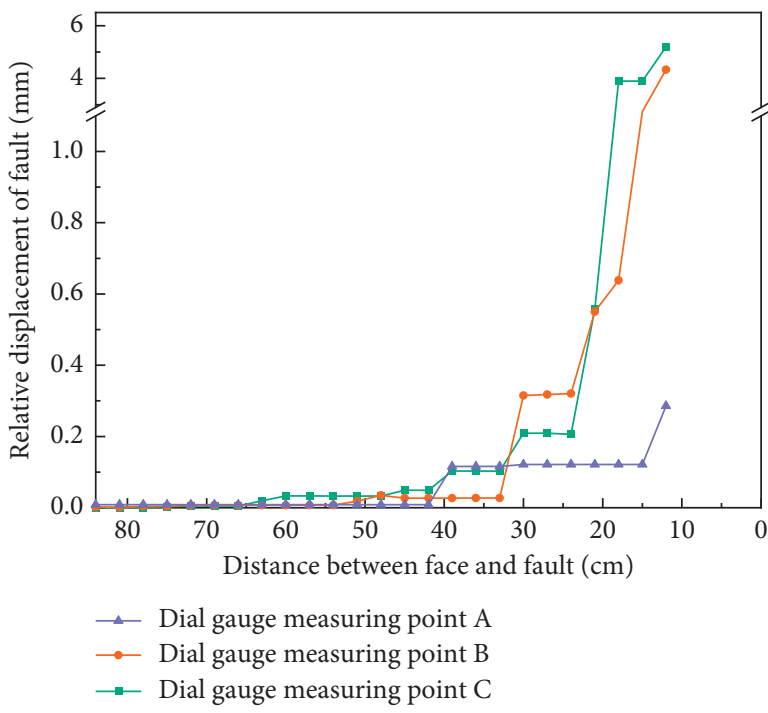

(a)

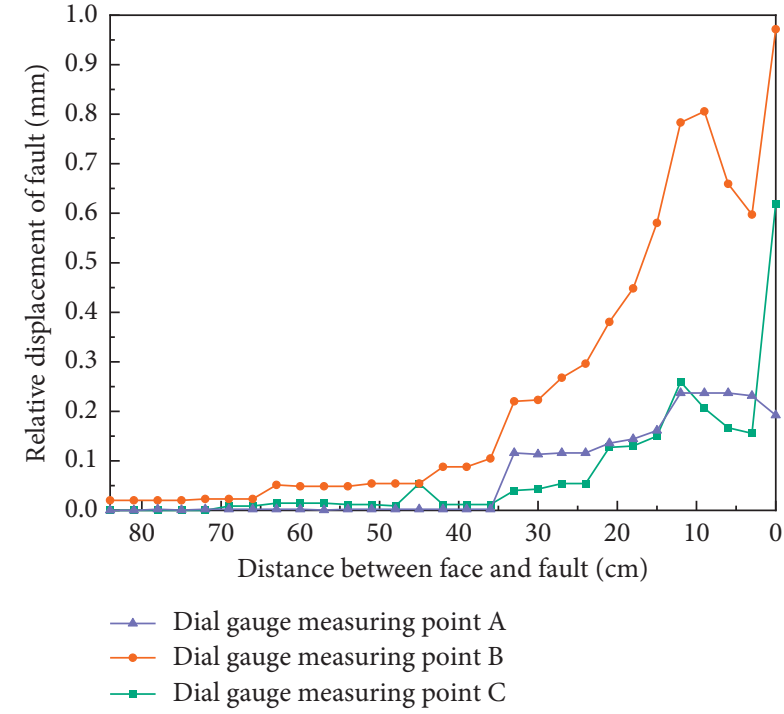

(b)

FIgUre 11: Relative displacements at the level of interruption of the extraction process. (a) Physical model I. (b) Physical model II.

The relative displacement of the fault in the upper region of the similar model I is larger, and the shear stress is released due to slip, which decreases the fiber strain value at the corresponding fault location, explaining the decrease of the peak fiber strain curve at the fault surface when it is close to the fault; meanwhile, the relative displacement of the fault in the lower region is small, indicating the concentration of shear stress in the lower part, which increases the corresponding fiber strain value, which corresponds to the fiber test where the peak fiber strain location is shifted to the lower part of the fault surface. This corresponds to the fiber test result that the peak position of fiber strain shifts to the lower part of the fault surface. Comprehensive analysis of the relative displacement between the faults and the fiber optic stress at the fault surface, similar to model I in which the picking motion makes the fault enter the activation state.

Comparative analysis shows that whether mining from the upper plate of the fault or the lower plate, the closer the working face to the fault, the greater the relative displacement between the faults, indicating that the mining disturbance affects the fault movement; the maximum relative displacement of the fault when the working face advances to the fault from the upper plate is much smaller than the displacement when the working face advances to the fault from the lower plate, indicating that the impact of the working face advancing to the fault from the lower plate on the fault structure is much greater than that when advancing from the upper plate impact, which is more likely to cause fault activation.

\section{Conclusions}

In this paper, similar model tests were carried out using the F16 positive fault in the southern part of the Yima coalfield as a prototype, and PPP-BOTDA was used to study the overburden deformation law and fault activation law for the working face located in the upper plate of the fault and the lower plate of the mining respectively. To sum up, the following conclusions are obtained in this paper.

(1) The key stratum breakage is closely related to the fault movement, and the range of shear stress concentration occurs within the key stratum. The additional shear stress concentration at the fault surface caused by the lower plate advance is much greater than that at the upper plate advance, which makes the fault more prone to instability during the advancement of the lower plate.

(2) The risk of fault activation and destabilization occurs in the lower plate advancement before the upper plate advancement. The rock layer on the upper part of the fault is affected by the mining of the working face before the lower part; the range of the working face affected by the fault is larger when the lower plate advances than when the upper plate advances.

(3) The distributed fiber optic sensing technology is used to verify the basic conclusion that the impact of the working face advancing from the lower plate to the fault is much greater than that when advancing from the upper plate, which is more likely to cause fault activation. The working face in the fault area is preferentially arranged in the upper plate, which is conducive to mine pressure control and ensures safe and efficient mining. It provides an experimental basis for the study of fault activation law using distributed fiber optic sensing method.

\section{Data Availability}

All the data, models, or codes that support the findings of this study are available from the corresponding author upon reasonable request. 


\section{Conflicts of Interest}

The authors declare that they have no conflicts of interest.

\section{Acknowledgments}

The authors are grateful for financial support from the Key Program of the National Natural Science Foundation of China (nos. 51804244, 41027002, and 51174280) and Scientific Research Project of Shaanxi Provincial Department of Education (16JK1488). Many thanks go to Professor J. Chai for the guidance in this paper. The authors would also like to thank Dr. Liu and Dr. Du for their valuable comments and suggestions for improving the manuscript.

\section{References}

[1] Q. Wang, M. C. He, S. C. Li et al., "Comparative study of model tests on automatically formed roadway and gob-side entry driving in deep coal mines," International Journal of Mining Science and Technology, vol. 31, no. 4, pp. 591-601, 2021.

[2] Q. Yin, J. Wu, C. Zhu, M. He, Q. Meng, and H. Jing, "Shear mechanical responses of sandstone exposed to high temperature under constant normal stiffness boundary conditions," Geomechanics and Geophysics for Geo-Energy and GeoResources, vol. 7, no. 2, p. 35, 2021.

[3] W. G. Du, J. Chai, D. D. Zhang, and W. L. Lei, "The study of water-resistant key strata stability detected by optic fiber sensing in shallow-buried coal seam," International Journal of Rock Mechanics and Mining Sciences, vol. 141, Article ID 104604, 2021.

[4] P. S. Zhang and B. Y. Sun, "Distribution characteristics of the advance abutment pressure in a deep stope," Journal of Geophysics and Engineering, vol. 17, pp. 1-14, 2020.

[5] C. Zhu, M. C. He, X. H. Zhang, Z. G. Tao, Q. Yin, and L. F. Li, "Nonlinear mechanical model of constant resistance and large deformation bolt and influence parameters analysis of constant resistance behavior," Rock and Soil Mechanics, vol. 42, no. 7, pp. 1911-1924, 2021.

[6] Z. Tao, Y. Shu, X. Yang, Y. Peng, Q. Chen, and H. Zhang, "Physical model test study on shear strength characteristics of slope sliding surface in nanfen open-pit mine," International Journal of Mining Science and Technology, vol. 30, no. 3, pp. 421-429, 2020.

[7] H. G. Ji, H. S. Ma, J. A. Wang, Y. H. Zhang, and H. Cao, "Mining disturbance effect and mining arrangements analysis of near-fault mining in high tectonic stress region," Safety Science, vol. 50, no. 4, pp. 649-654, 2012.

[8] N. B. Zhang, R. L. Shan, S. K. Zhao et al., "Experiment of thrust fault slipping under unloading," Journal of China Coal Society, vol. 46, no. 3, pp. 1-12, 2021.

[9] Y. D. Jiang, Y. S. Pan, and F. X. Jiang, "State of the art review on mechanism and prevention of coal bumps in China," Journal of China Coal Society, vol. 39, no. 2, pp. 205-213, 2014.

[10] C. W. Wang, F. X. Jiang, and J. H. Liu, "Analysis on control action of geologic structure on impact ground pressure and typical cases," Journal of China Coal Society, vol. 37, no. 2, pp. 263-268, 2012.

[11] M. Alber, R. Fritschen, M. Bischoff, and T. Meier, "Rock mechanical investigations of seismic events in a deep longwall coal mine," International Journal of Rock Mechanics and Mining Sciences, vol. 46, no. 2, pp. 408-420, 2009.

[12] T. WANG, S. Yu, and Y. Gao, "The Influence of different mining modes on the evolution law of Stress in Fault surrounding Rock," Journal of Mining and Safety Engineering, vol. 34, no. 2, pp. 276-281, 2017.
[13] Z. H. LI, L. M. Dou, and Z. Y. Lu, "Study of the fault slide destabilization induced by coal mining," Journal of Mining and Safety Engineering, vol. 27, no. 4, pp. 499-503, 2010.

[14] J. Chai, W. Du, Q. Yuan, and D. Zhang, "Analysis of test method for physical model test of mining based on optical fiber sensing technology detection," Optical Fiber Technology, vol. 48, pp. 84-94, 2019.

[15] D. Zhang, W. Du, J. Chai, and W. Lei, "Strain test performance of brillouin optical time domain analysis and fiber bragg grating based on calibration test," Sensors and Materials, vol. 33, no. 4, pp. 1387-1404, 2021.

[16] C. D. Piao, S. G. Lei, J. K. Yang, and L. H. Sang, "Experimental study on the movement and evolution of overburden strata under reamer-pillar coal mining based on distributed optical fiber monitoring," Energies, vol. 12, no. 77, pp. 1-12, 2019.

[17] R. A. Moffat, J. F. Beltran, and R. Herrera, "Applications of BOTDR fiber optics to the monitoring of underground Structures," Geomechanics and Engineering, vol. 9, no. 3, pp. 397-414, 2015.

[18] E. Buchoud, V. Vrabie, J. I. Mars et al., "Quantification of submillimeter displacements by distributed optical fiber sensors," IEEE Transactions on instrumentation and measurement, vol. 65, no. 2, pp. 413-422, 2016.

[19] I.-B. Kwon, S.-J. Baik, K. Im, and J.-W. Yu, "Development of fiber optic BOTDA sensor for intrusion detection," Sensors and Actuators A: Physical, vol. 101, no. 1-2, pp. 77-84, 2002.

[20] B.-j. Wang, K. Li, B. Shi, and G.-q. Wei, "Test on application of distributed fiber optic sensing technique into soil slope monitoring," Landslides, vol. 6, no. 1, pp. 61-68, 2009a.

[21] M. Iten and A. M. Puzrin, "BOTDA road-embedded strain sensing system for landslide boundary localization," Proceedings SPIE 7293, Smart Sensor Phenomena, Technology, Networks, and Systems, vol. 7293, Article ID 729316, 2009.

[22] T. Kurashima, T. Horiguchi, H. Izumita, S.-I. Furukawa, and Y. Koyamada, "Brillouin optical-fiber time-domain Reflectometry," IEICE-Transactions on Communications, vol. 76, no. 4, pp. 382-390, 1993.

[23] X. Bao, J. Dhliwayo, N. Heron, D. J. Webb, and D. A. Jackson, "Experimental and Theoretical studies on a Distributed Temperature sensor based on Brillouin scattering," Journal of Lightwave Technology, vol. 13, no. 7, pp. 1340-1348, 1995.

[24] Y. A. Vinogradov, V. E. Asming, E. O. Kremenetskaya, and D. V. Zhirov, "Modern seismicity in mining areas in the Murmansk Region," Journal of Mining Science, vol. 52, no. 1, pp. 46-52, 2016.

[25] Y. X. Zhao, H. Wang, Z. Lu, and B. Cao, "Characteristics of tremor time-space evolution and coulomb stress distribution along the fault during workface excavation," Journal of China Coal Society, vol. 43, no. 2, pp. 340-347, 2018.

[26] L. Kui, D. T. Arash, and D. L. Gao, "Calculation of hydraulic fracture induced stress and corresponding fault slippage in shale formation," Fuel, vol. 25, no. 4, pp. 1-12, 2019.

[27] Y. S. Pan, L. G. Wang, M. T. Zhang, and B. Y. Xu, "Theoretical and testing study of fault impact ground pressure," Chinese Journal of Rock Mechanics and Engineering, vol. 17, no. 6, pp. 642-649, 1998.

[28] K. Wu, G.-L. Cheng, and D.-W. Zhou, "Experimental research on dynamic movement in strata overlying coal mines using similar material modeling," Arabian Journal of Geosciences, vol. 8, no. 9, pp. 6521-6534, 2015.

[29] W. G. Du, J. Chai, D. D. Zhang, and W. L. Lei, "Application of optical fiber sensing technology in similar model test of Shallow-buried and thick coal seam mining," Measurement, vol. 181, Article ID 109559, 2021. 